\title{
Manual práctico para el diseño de la Escala Likert
}

\author{
Sandra Margarita Maldonado Luna*
}

sandram_maldonado@hotmail.com

Luz María Méndez Hinojosa

José Armando Peña Moreno

Trillas, 2007.

El libro es una guía detallada para la elaboración de un instrumento de medición llamado "escalamiento tipo Likert". Es un manual que muestra los principales usos en los que se puede emplear dicha escala, además de indicar paso a paso cómo elaborar y aplicar el instrumento de medición. Asimismo, incluye segmentos para que el lector pueda realizar ejercicios.

El texto se divide en nueve capítulos los cuales son: 1) Diseño de un instrumento de medición, 2) Identificación de la actitud o variable, 3) Elaboración de ítems relacionados con la actitud o variable que se requiere medir, 4) Administración de la escala a una muestra de jueces, 5) Asignación de puntajes a los ítems según su posición positiva o negativa, 6) Asignación de los puntajes a los jueces, 7) Análisis de los ítems: validación, 8) Análisis de los ítems: confiabilidad y 9) Interpretación.

La escala tipo Likert es un instrumento de medición o recolección de datos cuantitativos utilizado dentro de la investigación. Es un tipo de escala aditiva que corresponde a un nivel de medición ordinal; consiste en una serie de ítems o juicios a modo de afirmaciones ante los cuales se solicita la reacción del sujeto. El estímulo (ítem o juicio) que se presenta al sujeto, representa la propiedad que el investigador está interesado en medir y las respuestas son solicitadas en términos de grados de acuerdo o desacuerdo que el sujeto tenga con la sentencia en particular. Son cinco el número de opciones de respuesta más usado, donde a cada catego-ría se la asigna un valor numérico que llevará al sujeto a una puntuación total producto de las puntuaciones de todos los ítems. Dicha puntuación final indica la posición del sujeto dentro de la escala.

Las actitudes son lo que principalmente se pueden medir con una escala tipo Likert. Los pasos que se requieren seguir en la elaboración de una escala Likert son los siguientes: 1) conocer la actitud o variable a medir, 2) elaborar ítems relacionados con la actitud o variable que se quiere medir, 3) administrar la escala a una muestra de sujetos que van a actuar como jueces, 4) asignar los puntajes a los ítems según su posición positiva o negativa, 5) asignar los puntajes totales a los sujetos de acuerdo al tipo de respuesta en cada ítem, 6) efectuar el análisis de 
ítems (validación y confiabilidad), 7) construir con base en los ítems seleccionados la escala final, y 8) aplicar la escala final a la población en la cual se validó el instrumento.

Para diseñar cualquier instrumento de medición es necesario saber qué datos hay que recabar. Es decir, se debe indicar con precisión la actitud o variable a medir. Cabe mencionar que cualquier investigación es necesario tener claro cuál es el problema que se tiene, y los elementos para plantear dicho problema son tres y están relacionados entre sí: los objetivos que persigue la investigación, las preguntas de investigación y la justificación del estudio.

Cada ítem es un juicio o una sentencia a la cual el juez debe expresar su grado de acuerdo o desacuerdo. Aunque el número de opciones a cada ítem se recomienda que sea 5 , también pueden ser 2, 3, 4 y 7 .

Una vez elaborados los ítems, se deben aplicar a los jueces para poder validarlos. Para ellos se requiere integrarlos a una escala. Habiendo elaborado el instrumento, éste debe ser aplicado a una muestra entre cincuenta y cien jueces, los cuales deben ser seleccionados al azar de una población con características similares a aquélla en la cual se aplicará la escala final. Para poder aplicar la escala a los jueces, se deben incorporar cierta información necesaria como: a) datos de identificación de la organización para la cual se realiza la investigación, b) datos de identifi-cación de los jueces, c) presentación del estudio, y d) instrucciones.

Posteriormente, a la aplicación de la escala, se califica cada ítem como positivo o negativo, y luego se ponderan las alternativas de respuestas. Este paso consiste en codificar la información, es decir, darle un valor numérico a cada categoría de respuesta. Los valores numéricos para este tipo de escala pueden adoptar pesos distintos. Habiendo asignado pesos a cada ítem, se procede a la adjudicación de los puntajes totales para cada individuo en la muestra de jueces. Los puntajes totales resultan de la sumatoria de los puntajes ponderados para cada ítem.

Para validar la escala de la muestra aplicada, se seleccionan los cuartiles superiores e inferiores, es decir, el $25 \%$ de los sujetos con puntajes más elevados y el $25 \%$ de los sujetos con puntajes más bajos. A estas dos submuestras se les aplica el estadístico t de Srudent, la cual es una prueba estadística para evaluar si dos grupos difieren entre sí de manera significativa respecto a sus medias. Si el resultado se encuentra entre un valor positivo y uno negativo, la escala es válida y formará parte de la escala final.

Además de que se requiere que la escala sea válida, también es preciso que tenga un grado determinado de confiabilidad. La confiabilidad se refiere al grado 
en que su aplicación repetida al mismo sujeto u objeto produce resultados iguales. El método sugerido para determinar la confiabilidad de la escala tipo Likert es el método de mitades partidas (split-halves).

Después de determinar la validez y confiabilidad de la escala, se puede proceder a levantar el instrumento de medición a la población objetivo. Se codifica la información y se interpretan los datos obtenidos.

El libro es muy amigable, explica a detalle todos los pasos para elaborar un instrumento de medición tipo Likert. Es una ayuda útil para personas que conocen poco o nada del tema. Es de especial interés para estudiantes que estén desarrollando cualquier proyecto de investigación, principalmente cuantitativo. 